\title{
Fibrosing alveolitis with autoimmune haemolytic anaemia: two case reports
}

\author{
J. W. SCADDING ${ }^{1}$ \\ From Brompton Hospital, London
}

Scadding, J. W. (1977). Thorax, 32, 134-139. Fibrosing alveolitis with autoimmune haemolytic anaemia: two case reports. Two patients with fibrosing alveolitis and autoimmune haemolytic anaemia are described. One patient also had neurofibromatosis. The haematological associations of fibrosing alveolitis are discussed, and a possible relationship between autoimmune haemolysis and fibrosing alveolitis is suggested.

In the last few years cryptogenic fibrosing alveolitis has been described in association with many different diseases (see reviews of Turner Warwick (1972) and Scadding (1974) but there has been special interest in systemic disorders involving abnormal immune mechanisms, particularly rheumatoid arthritis and systemic lupus erythematosus (Turner Warwick, 1974). Immunofluorescent studies on lung biopsies in patients with 'lone' fibrosing alveolitis, but with circulating antinuclear antibody in the sera, have shown deposits of gamma globulin and complement in alveolar walls (Turner Warwick and Haslam, 1971), and it has been postulated that immune complex deposition in alveolar walls may be the initiating factor in alveolar wall fibrosis in these patients (Turner Warwick, 1974). In autoimmune haemolytic anaemia, abnormal cell-bound circulating antibody is responsible for haemolysis. This pathological process has not previously been reported in association with fibrosing alveolitis. Two patients showing this association are reported here.

\section{Case reports}

\section{CASE 1}

A 62-year-old man was first admitted to hospital in November 1973 for stripping of varicose veins. Investigations included a haemoglobin of $14.4 \mathrm{~g} / \mathrm{dl}$ and a chest radiograph, reported as showing minimal mottling at both bases. Ten days postoperatively he developed right-sided pleuritic pain, fever, and a dry cough. This resolved with antibiotic treatment. In February 1974, a follow-up radio-

'Present address: University College Hospital, Gower Street, London WC1 graph showed persisting basal shadowing (Fig. 1) $\stackrel{\vec{\vartheta}}{\vartheta}$ at a time when the patient was asymptomatic. In . July 1974 he had recurrent right-sided pleurisy with fever, cough, and purulent sputum, again successfully treated with antibiotics. In November $\frac{}{0}$ 1974 , over a three-week period he developed severe symptoms of malaise, exertional dyspnoea, and $\stackrel{\odot}{\propto}$ exertional calf pain. He had lost 2 stones $(12 \cdot 7 \mathrm{~kg}) \stackrel{2}{\Rightarrow}$ in weight over the previous year. He smoked $15 \stackrel{\circ}{3}$ cigarettes daily. A family history revealed that his brother and maternal aunt both had pernicious anaemia.

He was referred to Brompton Hospital in December 1974 when, on examination, he was $\underset{x}{\stackrel{0}{x}}$ very pale and slightly jaundiced, and there was $\dot{\sigma}$ finger clubbing. There were several small peduncu- 3 . lated fleshy skin lesions on the trunk. Tongue and $\delta$ buccal mucosa were normal, and there was no lymphadenopathy nor arthritis. In the chest there o were bilateral basal fine inspiratory crackles. There was mild bilateral ankle oedema and an apicalo mid-systolic cardiac murmur. A firm liver edge was palpable $4 \mathrm{~cm}$ below the right costal margin but $ᄋ$ the spleen was not palpable.

A chest radiograph taken in December 1974 is shown (Fig. 2). Lung function at this time is given in the second column of the Table, showing reduced volumes and a marked decrease in gas transfer. Arterial gases on air at rest were $\mathrm{Po}_{2} \stackrel{\oplus}{\rightarrow}$ $11.1 \mathrm{kPa}(83 \mathrm{mmHg})$ and $\mathrm{PCO}_{2} 5.1 \mathrm{kPa}\left(38_{0}\right.$ $\mathrm{mmHg}$ ). Histology of a lung biopsy showed the changes of fibrosing alveolitis, predominantly mural but with quite marked desquamation in $\frac{}{\mathbb{D}}$ places (Fig. 3).

Haemoglobin was $5 \cdot 1 \mathrm{~g} / \mathrm{dl}$, white blood count $7.8 \times 10^{9} 1^{-1}(7800 / \mu 1)$, with a normal differential;o 


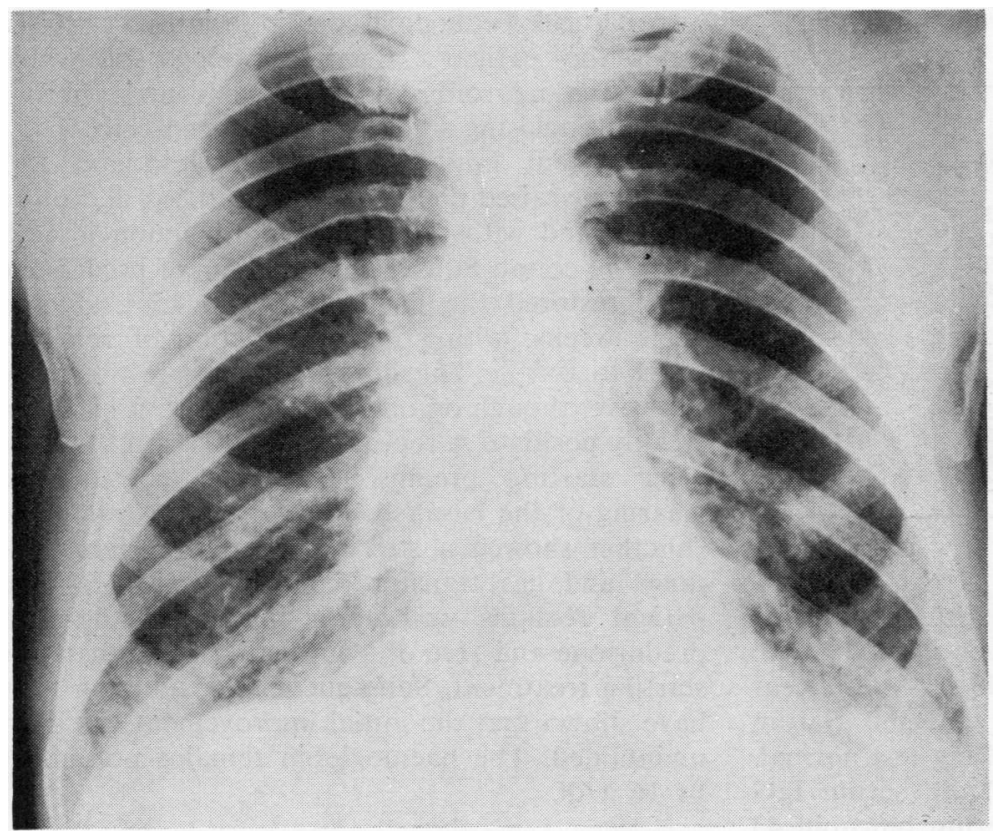

Fig. 1 Case 1. Chest radiograph in February 1974 showing bilateral lower zone shadowing.



Fig. 2 Case 1. Chest radiograph in December 1974 showing persistent bilateral basal shadowing.

platelets $203.0 \times 10^{9} \mathrm{l}^{-1}(203000 / \mu \mathrm{l})$, ESR $40 \mathrm{~mm} / \mathrm{l}$ hour. A blood film revealed $32 \%$ reticulocytes with 8 normoblasts per 100 leucocytes. Sternal marrow aspirate showed very active erythropoiesis, partly megaloblastic, with depressed granulopoiesis. The direct Coombs' test was positive due to
IgG on the red cell surface. On elution this IgG had marked Rhesus specificity with some anti-'e' specificity (Rhesus phenotype cde/cde). The serum contained autoantibody reacting against enzymetreated red cells. Red cell survival studies (chromium-51) showed a red cell half-life of only 4 days 
Table Patient 1. Lung function before and after treatment with prednisone

\begin{tabular}{|c|c|c|c|}
\hline & Predicted & Patient & $\begin{array}{l}\text { Patient after } \\
14 \text { days on } \\
\text { prednisone }\end{array}$ \\
\hline $\mathrm{FEV}_{1}(\mathrm{ml})$ & 2380 & 2380 & 2750 \\
\hline FVC (ml) & 3240 & 3000 & 3500 \\
\hline $\mathrm{FEV}_{1} / \mathrm{FVC}$ & $69 \cdot 5$ & $79 \cdot 3$ & $78 \cdot 6$ \\
\hline VC (ml) & 3420 & 2650 & 3100 \\
\hline FRC (ml) & 3230 & 1790 & 2800 \\
\hline TLC (ml) & 5440 & 3390 & 4650 \\
\hline$V_{A}(\mathrm{ml})$ & - & 3860 & 4080 \\
\hline DLco $\left(\mathrm{ml} \mathrm{min}^{-1}\right.$ torr -1$)$ & $19 \cdot 3$ & $9 \cdot 2$ & $13 \cdot 8$ \\
\hline$\left(\mathrm{mmol} \mathrm{min}^{-1} \mathrm{kPa}^{-1}\right)$ & $6 \cdot 5$ & $3 \cdot 0$ & $4 \cdot 6$ \\
\hline $\mathrm{Kco}\left(\min ^{-1}\right.$ torr $\left.^{-1}\right)$ & $4 \cdot 14$ & $2 \cdot 4$ & $\mathbf{3 \cdot 3 8}$ \\
\hline$\left(\min ^{-1} \mathrm{kPa}^{-1}\right)$ & 31.05 & $18 \cdot 0$ & $25 \cdot 35$ \\
\hline $\mathrm{Hb}(\mathrm{g} / \mathrm{dl})$ & - & $5 \cdot 1$ & 11.9 \\
\hline
\end{tabular}

(normal 25-32 days), and body surface counting showed marked excess counts over the liver with no significant uptake over the spleen. Antinuclear antibody and LE cells were not detected. Serum B12 $152 \mathrm{ng}^{-1}(152 \mathrm{pg} / \mathrm{ml})$, Schilling test normal. Serum folate $1.6 \mu \mathrm{g} 1^{-1}(1.6 \mathrm{ng} / \mathrm{ml})$, serum IgG $197.4 \mathrm{~g}^{-1}(1974 \mathrm{mg} / 100 \mathrm{ml})$, serum bilirubin 43 $\mu \mathrm{mol} 1^{-1}(2.5 \mathrm{mg} / 100 \mathrm{ml})$, urine haemosiderin positive.
A painful, pedunculated skin lesion was excised $\stackrel{\overrightarrow{\vec{F}}}{+}$ from the patient's trunk, histology of which showed a neurofibroma with concentric fibrous strands enclosing small spindle-shaped cells.

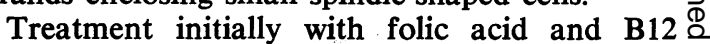
injections raised the haemoglobin to $8 \mathrm{~g} / \mathrm{dl}$, but no higher, and with no significant reduction in reti- $\vec{\circ}$ culocyte count. Subsequently, $60 \mathrm{mg}$ of prednisone daily restored the haemoglobin to $15 \mathrm{~g} / \mathrm{dl}$ over $\vec{\omega}$ three weeks, with gradual reduction of reticulo- 2 cytes to $0-2 \%$. The direct Coombs' test became $\vec{x}$ negative, though on one occasion since it has been $\omega_{N}$ weakly positive. A repeat chest radiograph 14 days $i$ after starting prednisone showed considerable $\vec{\omega}$ clearing of the basal shadowing (Fig. 4), and lung + function showed a striking increase in lung vol- 음 umes and gas transfer (column 3, Table). The $\rightarrow$ patient remains well on a small daily dose of $\frac{D}{O}$ prednisone and free of symptoms 10 months after starting treatment. Subsequent lung function tests $\vec{\theta}$ have shown that the initial improvement has been $\searrow$ maintained. The haemoglobin remains normal at $14-16 \mathrm{~g} / \mathrm{dl}$.

CASE 2

A 76-year-old man was found to have right apical $\stackrel{2}{\circ}$

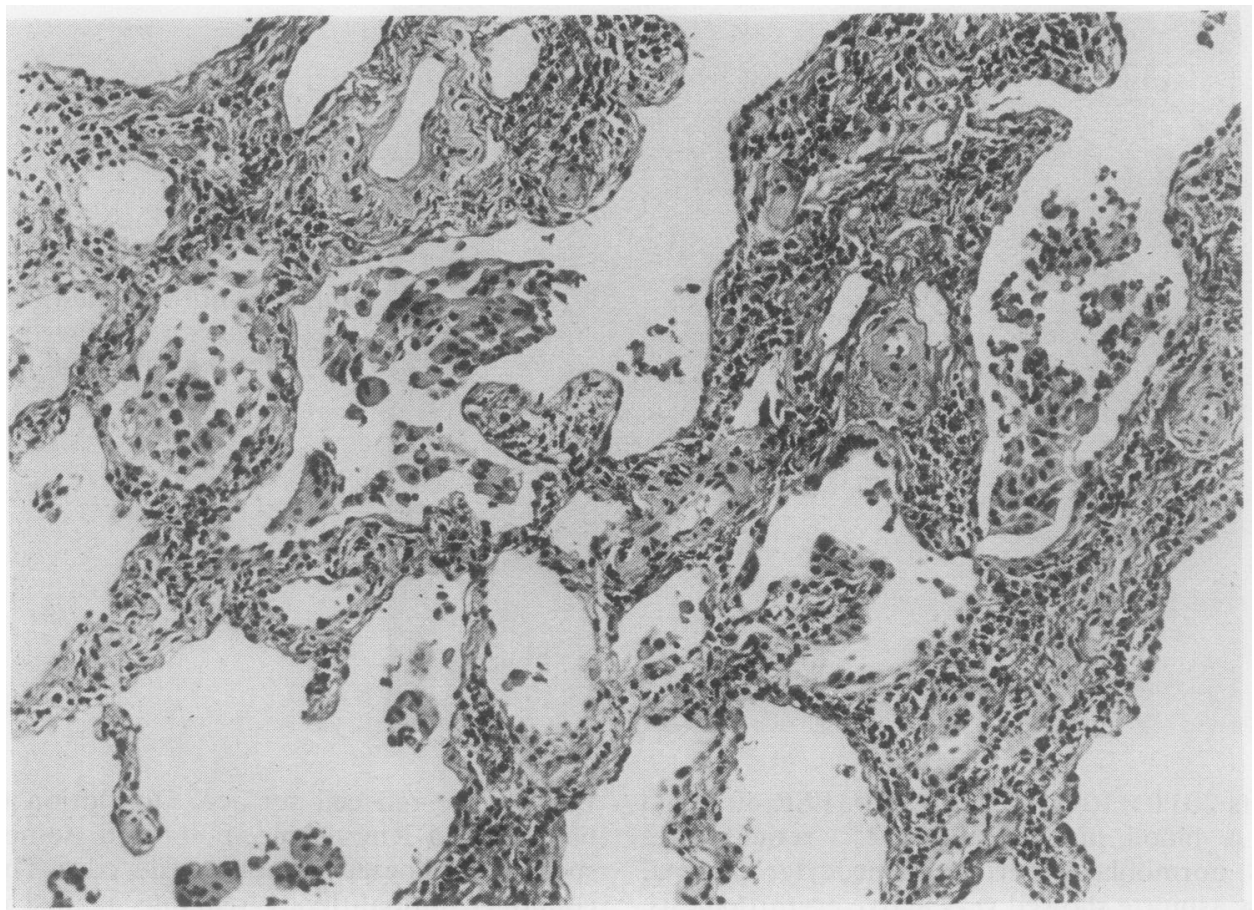

Fig. 3 Case 1. Lung biopsy in January 1975. Fibrosing alveolitis, showing mural thickening and an area of desquamative change. Haematoxylin and eosin $\times 170$. 


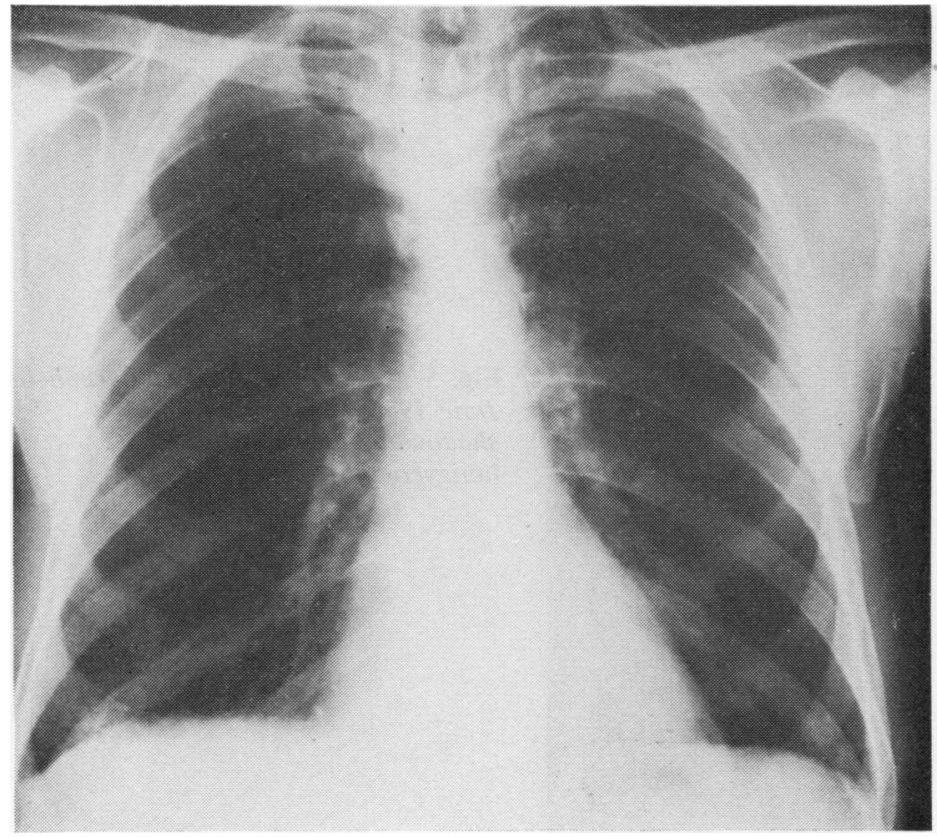

Fig. 4 Case 1. Chest radiograph 14 days after the beginning of prednisone treatment, showing clearing of lower zone shadowing.

lung shadowing at mass radiography in 1959 which was thought to be an inactive tuberculous lesion. Follow-up films showed no change, and no treatment was given. In 1967 he was investigated for symptoms of breathlessness, cough with sputum, and malaise. A chest radiograph again showed right apical shadowing. Tests for tuberculosis were negative, including a sputum smear and culture and a negative Heaf test. $\mathrm{He}$ was found to be anaemic with a haemoglobin of $60 \%$ and $6 \%$ reticulocytes and a strongly positive direct Coombs' test. A diagnosis of autoimmune haemolytic anaemia was made and he was treated with $30 \mathrm{mg}$ of prednisone daily, with para-aminosalicylic acid and isoniazid cover. There was no reduction in haemolysis after two months, and all the drugs were stopped.

The patient complained of increasing dyspnoea, and chest radiographs over the next few months showed a gradually extending reticular shadowing in both lungs. Sputum was again negative for acidfast bacilli and malignant cells. The patient was referred to Hammersmith Hospital in June 1968. On examination he was pale, but not dyspnoeic or cyanosed, and there was no finger clubbing. Crackles were present throughout both lungs, particularly basal. A chest radiograph (Fig. 5) showed diffuse widespread reticular shadowing with some coarse basal honeycombing and persistent right apical shadowing. Tomography of the right apex showed thickened interstitial septa but no cavity formation. Lung function showed a vital capacity of 2.3 litres, forced expiratory volume in one second $2 \cdot 151$, total lung capacity 4.01 , transfer factor (DLCO) $7.26 \mathrm{ml} / \mathrm{min} / \mathrm{mmHg}\left(2.4 \mathrm{mmol} \mathrm{min}^{-1}\right.$ $\mathrm{kPa}^{-1}$ ) (predicted $23 ; 7 \cdot 7$ ), and transfer factor per litre of lung volume (Kco) $2.28 \mathrm{~min}^{-1}$ torr $^{-1}$ (17.1 $\left.\min ^{-1} \mathrm{kPa}^{-1}\right)$. Peak expiratory flow rate was 460 $1 / \mathrm{min}$. Bronchoscopy and bronchial biopsy were normal. In view of his age lung biopsy was not performed. The diagnosis made was fibrosing alveolitis. Haematological investigations revealed a haemoglobin of $10.9 \mathrm{~g} / \mathrm{dl}$ with $7.2 \%$ reticulocytes, normal white count and differential; ESR 104 $\mathrm{mm} / 1$ hour. Direct Coombs' test was strongly positive. Antibody eluted from the red cells gave a strongly positive indirect Coombs' test and showed anti-'e' specificity (Rhesus phenotype cde/ cde). Serum IgG was $24.00 \mathrm{~g}^{-1}(2400 \mathrm{mg} / 100 \mathrm{ml})$ and serum bilirubin $19 \mu \mathrm{mol} 1^{-1}(1 \cdot 1 \mathrm{mg} / 100 \mathrm{ml})$. Antinuclear antibody and LE cells were not detected. The results were typical of autoallergic haemolytic anaemia. Following these investigations the patient became lost to follow-up and no further clinical details are available.

\section{Discussion}

Few haematological abnormalities have been described in association with fibrosing alveolitis. In 
a series of 154 patients with fibrosing alveolitis, Turner Warwick (1972) recorded one patient with myelosclerosis, two with purpura, two with pernicious anaemia, and one with folic acid deficiency. Gumpel (1971) described a patient with fibrosing alveolitis, Sjögren's syndrome, Waldenström's hypergammaglobulinaemia, and immune paresis. The association of autoimmune haemolytic anaemia with fibrosing alveolitis has not been described before, and this observation is of interest in view of the recent speculation that fibrosing alveolitis may, in some cases at least, be initiated by immune complex deposition in alveolar walls. However, circulating immune complexes are not formed in autoimmune haemolysis: the abnormal autoantibody, usually IgG, attaches to red cells, fixing complement to a variable degree. The coated red cells then become attached to splenic macrophages, which have specific receptor sites for IgG (LoBuglio et al., 1967). After attachment the red cells are either lysed, or part of the membrane is removed, with the formation of spheroid cells that are more susceptible to subsequent splenic destruction. A similar process of macrophage attachment is known to occur in the circulation, liver, and bone marrow (Dacie and Worlledge, 1975).

It is probable that pulmonary macrophages are also involved in this process since it has been shown that these cells originate in the bone marrow
Fig. 5 Case 2. Chest radiograph in June 1968. Widespread diffuse shadowing with lower zone honeycombing. and may therefore be expected to share their func- $\stackrel{\varnothing}{\complement}$ tional characteristics. For example, Pinkett et al. $\overrightarrow{\overrightarrow{0}}$ (1966), using chromosome-labelled mouse macro- 3 phages, found that between $60 \%$ and $80 \%$ of free alveolar macrophages were derived from labelled bone marrow mononuclear cells. Bowden et al. (1969) and Velo and Spector (1973), using tritiated-으 thymidine-labelled macrophages, confirmed the bone marrow origin of free alveolar macrophages and found that before migration into alveolar spaces these cells spent two to three days withinô alveolar walls, presumably undergoing a process of further maturation. It is considered that a을 normal function of pulmonary macrophages is the removal of old red cells from the circulation (Spencer, 1968), and it seems likely that this activity is intensified in autoimmune haemolysis. It is suggested that an active phagocytosis by cir- $N$ culating macrophages and by macrophages in alveolar walls, with ingestion or red cell fragmentso containing immune complexes, may give rise too an inflammatory reaction within alveolar walls, leading eventually to fibrosis. In the first patient? described here, red cell survival studies showedo no excess destruction of cells by the spleen (showno to be present radiologically), with large excess counts over the liver, an unusual situation in auto $\overrightarrow{\mathbb{Q}}$ immune haemolytic anaemia. It may be that, in the absence of red cell destruction in the spleen haemolysis occurs to a greater degree in extra응 
splenic sites, including liver and lungs. However, staining for haemosiderin in the lung biopsy from patient 1 did not show excessive deposits which might be expected in active haemolysis within the lungs.

It is possible that the fibrosing alveolitis in the two patients here occurred coincidentally with the autoimmune haemolytic anaemia, but the diseases are both uncommon and this raises the question of a pathological relationship. An alternative explanation in the first patient is that the fibrosing alveolitis was associated with the neurofibromatosis, now a well-recognised association (Massaro and Katz, 1966). In the first patient the dramatic response of the pulmonary abnormalities, as measured by lung function tests and radiographic appearances, and the rapid improvement in the anaemia, occurred concurrently with prednisone, but this in itself cannot be taken as evidence of a pathological relationship between the two conditions. Corrections of the anaemia would lead to an improvement in gas transfer in the lungs (Cotes, 1965), but the improvement measured here is greater than would be due to such a correction alone, and the increase in lung volume and radiographic appearance both suggest an improvement in the fibrosing alveolitis itself.

The folate deficiency in this patient, and the initial response of his anaemia to folate therapy, are in keeping with the view of Chanarin et al. (1959) that folate deficiency is common in severe haemolytic states, leading to megaloblastic erythropoiesis as a result of an increased requirement of folic acid.

I am grateful to Dr. J. C. Batten and Professor C. M. Fletcher for permission to report details of patients under their care, to Dr. Shelia Worlledge for performing the immunological studies in the first patient, to Dr. B. Heard for helpful comments on the histology, and to Mr. K. Moreman for the photomicrographs.

\section{References}

Bowden, D. H., Adamson, I. Y. R., Grantham, W. G., and Wyatt. J. P. (1969). Origin of the lung macrophage: evidence derived from radiation injury. Archives of Pathology, 88, 540-546.
Chanarin, I., Dacie, J. V.. and Mollin, D. L. (1959). Folic-acid deficiency in haemolytic anaem:a. British Journal of Haematoloy, 5, 245-256.

Cotes, J. E. (1965). Lung Function, Assessment and Application in Medicine, chapter 8, p. 185 et seq. Blackwell Scientific Publications, Oxford.

Dacie, J. V. and Worlledge, S. M. (1975). Autoallergic blood diseases. In Clinical Aspects of Immunology, edited by P. G. H. Gell, R. R. A. Coombs, and P. J. Lachmann, 3rd edition, pp. 11491182. Blackwell. Oxford.

Gumpel, J. M. (1971). Sjögren's syndrome with pulmonary fibrosis, Waldenström's hyperglobulinaemic purpura and immune paresis. Proceedings of the Royal Society of Medicine, 64, 397.

LoBuglio, A. F., Cotran, R. S., and Jandl, J. H. (1967). Red cells coated with immunoglobulin G: binding and sphering by mononuclear cells in man. Science, 158, 1582-1585.

Massaro, D. and Katz, S. (1966). Fibrcsing alveolitis: its occurrence roentgenographic and pathologic features in Von Recklinghausen's neurofibromatosis. American Review of Respiratory Disease, 93, 934942.

Pinkett, M. O., Cowdrey, C. R., and Nowell, P. C. (1966). Mixed hematopoietic and pulmonary origin of 'alveolar macrophages' as demonstrated by chromosome markers. American Journal of Pathology, 48, 859-867.

Scadding, J. G. (1974). Diffuse pulmonary alveolar fibrosis. Thorax, 29, 271-281.

Spencer, H. (1968). Pathology of the Lung, 2nd edition, p. 38 et seq. Pergamon Press, Oxford.

Turner-Warwick, M. (1972). Cryptogenic fibrosing alveolitis. British Journal of Hospital Medicine, 7, 697-704.

Turner-Warwick, M. (1974). Immunological aspects of systemic diseases of the lungs. Proceedings of the Royal Society of Medicine, 67, 541-547.

Turner-Warvick. M. and Haslam, P. (1971). Antibodies in some chronic fibrosing lung diseases. 1. Non organ-specific autoantibodies. Clinical Allergy, 1, 83-95.

Velo, G. P. and Spector, W. G. (1973). The origin and turnover of alveolar macrophages in experimental pneumonia. Journal of Pathology, 109, 7-19.

Requests for reprints to: Dr. J. W. Scadding, University College Hospital, Gower Street, London WC1. 